\title{
Learning from traditional architecture
}

\author{
S. Schelbach \& U. Dietrich \\ HafenCity Universität, Hamburg, Germany
}

\begin{abstract}
This investigation tries to find the most important strategies for passive measures looking at traditionally built houses in the upper town of Thessaloniki in northern Greece.

The buildings were analysed with simulation tools to learn about the effect of the building materials, the form and size of the windows and the natural ventilation and the location of the buildings inside the city for the thermal comfort which is known as very good.

The result of the investigation will be the basis for a planning guideline for renovation of houses with a low energy standard and recommendations for new buildings. Many houses in northern Greece have a very high energy demand concerning both heating and cooling. The guideline will help architects and planners to develop design and refurbishment concepts using strategies which have already been used in this region for a long time.

The method of transferring passive strategies found by looking at traditional architecture is shown by the example of northern Greece, but can be used for other regions in the same or similar way.

Keywords: traditional architecture, vernacular architecture, passive cooling, sustainable, natural ventilation, thermal comfort.
\end{abstract}

\section{Introduction}

There is so much we can learn by looking at traditional architecture. Our ancestors found many solutions for sustainable buildings regarding energy and resource efficiency. Many surveys show an analysis of this climate adapted architecture but in most cases they do not make a statement about how to use this knowledge today.

This part of a $\mathrm{PhD}$ Thesis tries to find the most important strategies for passive measures looking at traditionally built houses in the upper town of 
Thessaloniki in northern Greece. The style of these houses is named "Makedonian Architecture" and can be found in northern Greece as well as in neighbouring regions. It is well known that these houses have a good thermal comfort for the people living there.

The climate in northern Greece can be described as cold in the winter with a relative humidity of up to $80 \%$ and warm and dry in the summer as shown in Table 1. This investigation concentrates on the thermal comfort in the summer. A climate responsive building prevents overheating in the warm season.

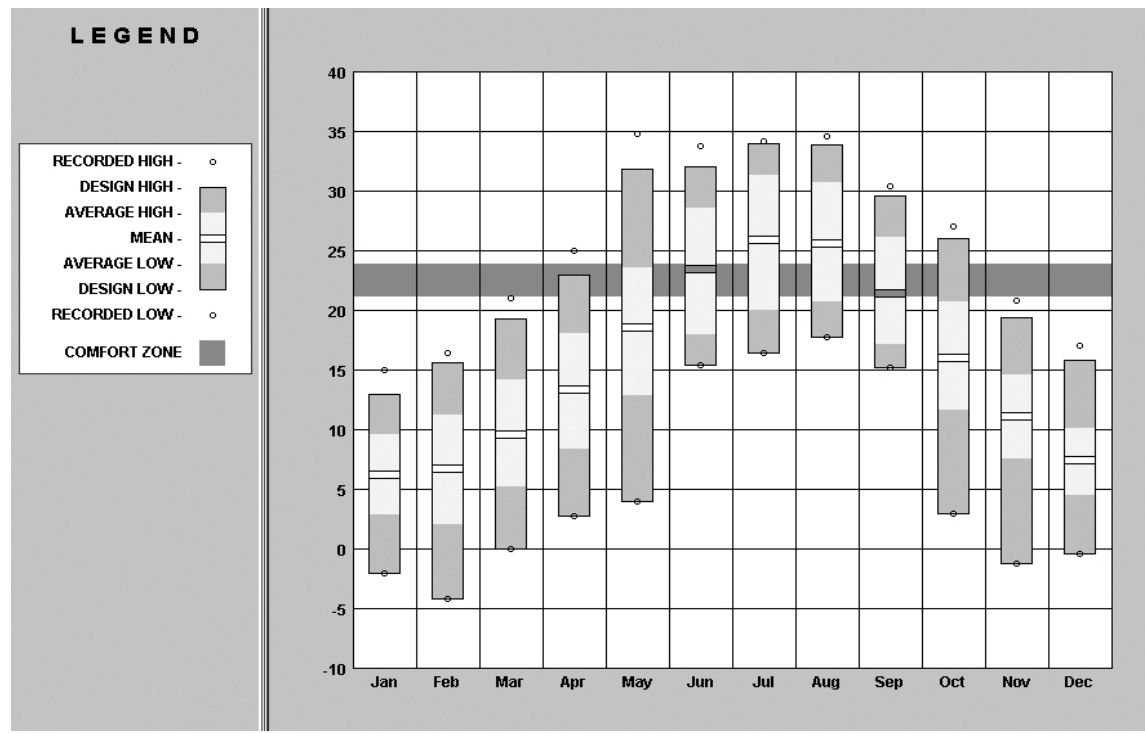

Figure 1: $\quad$ Climate chart of Thessaloniki, temperature in ${ }^{\circ} \mathrm{C}$. (Source: Climate Consultant 5.1, University of California, Los Angeles, USA, http://www.energy-design-tools.aud.ucla.edu/.)

\section{Approach}

\subsection{Database}

The building simulation requires data about the building structure, the urban context and climate data. Following an architectural survey, two buildings which can be described as typical houses in the upper town of Thessaloniki have been investigated.

\subsubsection{Building structure and urban context}

Both houses have been built by Turkish families in the 19th century and show a similar structure. The ground floor structures are made of massive natural stone masonry with small openings. The walls are approx. $70 \mathrm{~cm}$ thick. One or two upper floors are built as a light structure, made of timber framework and brick 
masonry with plaster on both sides. The walls are painted in light colours. The roofs are covered with tiles and have an overhang of about $60 \mathrm{~cm}$. All houses have at least one jutty, facing the street. The streets are narrow and curvy, ascending towards the hilltop. Building 1 is a two storey house in Epimenidou Street and building 2 a three storey house in Raktivan Street. The buildings are in an urban context of a densely built surrounding on a slope, facing the sea.

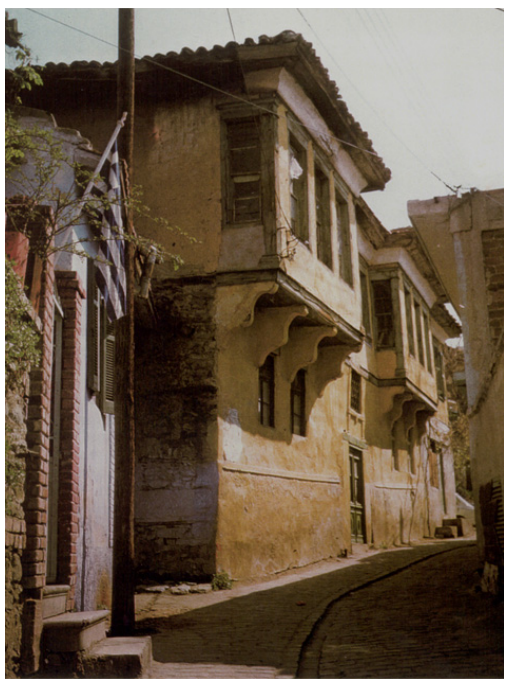

A

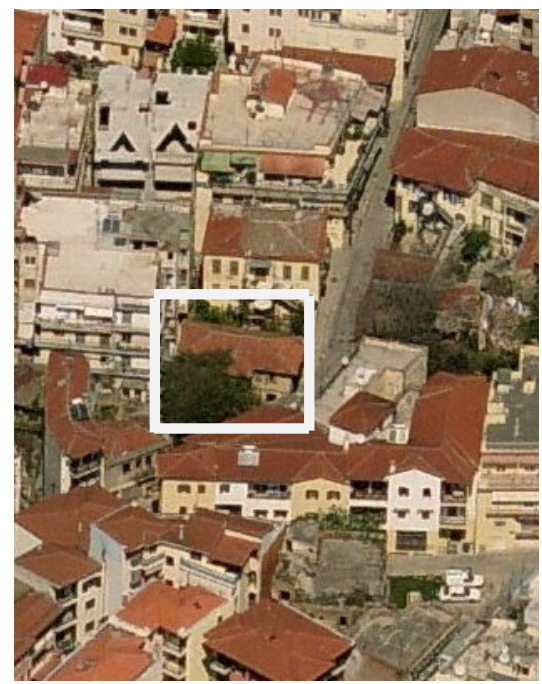

B

Figure 2: A. Bldg. 1 in Epimenidou Street, Thessaloniki (picture by Michael Nomikos). B. Bldg. 2 in Raktivan Street, Thessaloniki (source: http://www.kapou.gr/).

\subsubsection{Climate data}

Concerning the climate data two different data bases have been investigated. One available record consisted out of generated data and was available from Meteonorm [1]. The other database with recorded data was taken from Energy Plus [2]. Looking closer at the two databases it was found, that the Meteonorm database does not seem to correlate with the existing situation of the wind speed and direction. The wind wheel shows wind at high speed coming from each direction in nearly equal measures (Fig. 3).

The Energy Plus database seems to illustrate the existing situation. In the winter there is cool or cold wind coming from northern and western directions, only sometimes from the east. Warm wind in the summer time is mainly coming from the south. This shows that it is very important to check the available databases to be sure they contain the local specialities. For the simulation of the natural ventilation and the temperature inside the buildings the recorded data have been used. 

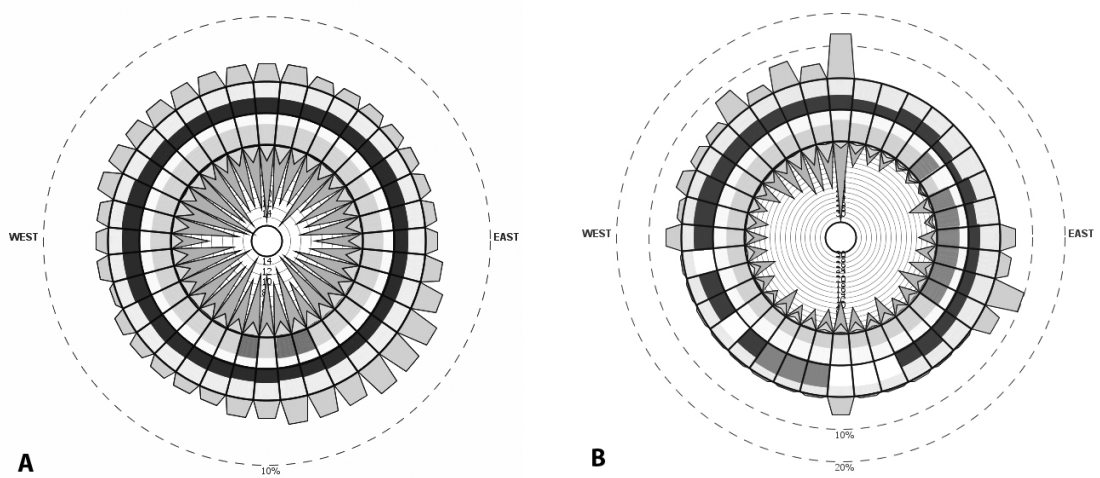

Figure 3: Wind Wheels, A: generated climate data, B: recorded climate data. (Source: Climate Consultant 5.1, University of California, Los Angeles, USA, http://www.energy-design-tools.aud.ucla.edu/.)

\subsection{Natural ventilation}

The ventilation of a room is important for the user concerning the air quality and the temperature. For the building itself sufficient ventilation is essential to keep the construction dry. Ventilation in the houses in the upper town of Thessaloniki is provided through the windows. The ground floor with the massive structure has small openings to keep the warm air in at winter time. The upper floor(s) have wide openings to provide as much ventilation as possible to avoid overheating in the summer.

The openings of the upper floor have hinged windows with wooden slat blinds on the outside for shading. These give the user the possibility of shading without blocking the ventilation of the room. The slat blinds also provide the opportunity of night ventilation giving protection against burglary.

The British Standard BS 5925-1991 "Code of practice for ventilation principles and designing for natural ventilation" [3] offers a possibility to estimate the ventilation of a room. The calculation method does not include the depth of the room or internal obstacles.

In this research it was extended with an adaptive window-opening algorithm [4] because the BS model only calculates the maximum air exchange rate which is possible to reach per hour with all windows open. The algorithm includes the probability that the user will open or close windows according to the wind speed and the indoor and outdoor temperature for more comfort. It is based on the knowledge of the inside and outside temperature and shows the probability of the opening of the windows for cooling or closing them to avoid cold discomfort.

\section{Calculations}

\subsection{Estimation of the natural air change}

Using the recorded climate data the calculation of the hourly air exchange rate 
was calculated using the wind direction, the wind speed in $\mathrm{m} / \mathrm{s}$ and the outside air temperature. In the first example a room in the building in Epinemidou was investigated (Fig. 4A). This room faces the street with three windows, each with $1,4 \mathrm{~m}^{2}$. To the back yard there is a small window with only $0,17 \mathrm{~m}^{2}$.

The calculation of the hourly air change rate for the summer time (MaySeptember) shows a very high exchange rate even though the window-opening algorithm is included and the window to the back yard is very small and the cill height is $1,80 \mathrm{~m}$.

In building 2, Raktivan Street a room with a jutty facing the street was calculated (Fig. 4B). It also has bigger openings on one side and a smaller one on the other. The result is mainly the same, the air exchange rate for the summer months is a minimum of $10 / \mathrm{h}$ although one window is very small. Figure 6 visualises the situation with and without cross ventilation, in case the small window is not existent.
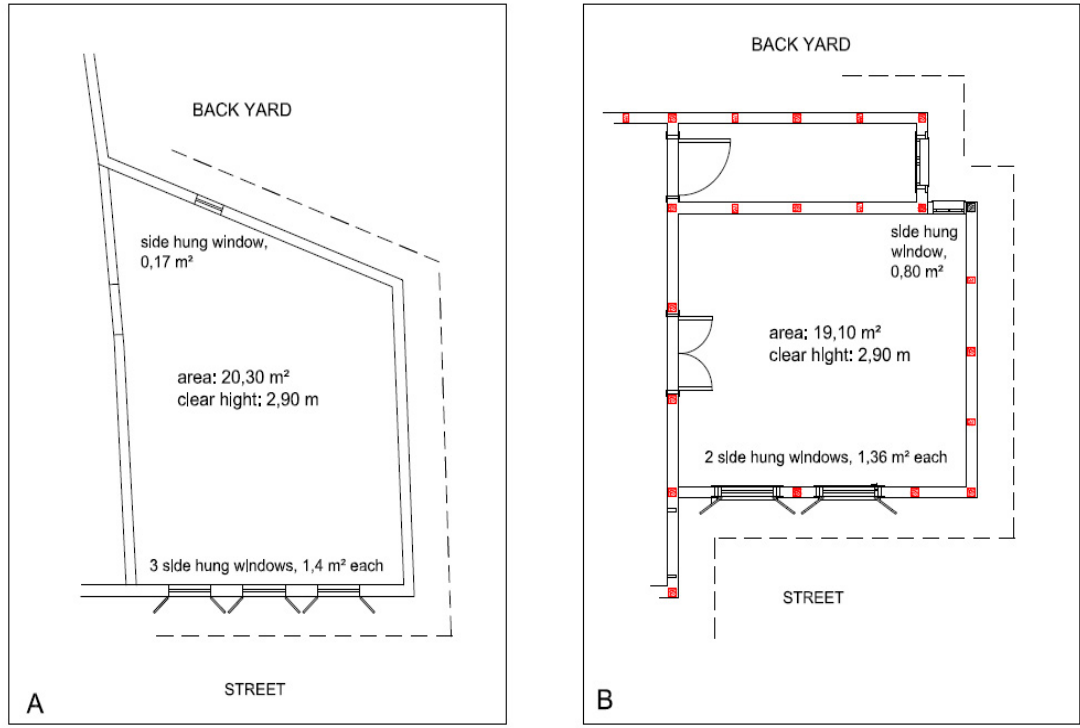

Figure 4: $\quad$ A: Room in Epinemidou Street; B: Room in Raktivan Street.

\subsection{Building simulation}

The estimation of the air exchange showed a very high rate for the rooms. Even if the shutters at the windows are closed frequently, a high rate of $4,5 / \mathrm{h}$ for the ventilation of the rooms can be assumed. For the building simulation no heating system was inserted to show the reaction of the building to the outdoor temperature. The construction materials, windows and internal heat gains were inserted into the program PRIMERO 1.0 [5] as they have been in the original 
state of the building. The calculations were made for the 2 nd floor of the building in Raktivan Street.

Air exchange rate in $1 / \mathrm{h}$, May - September

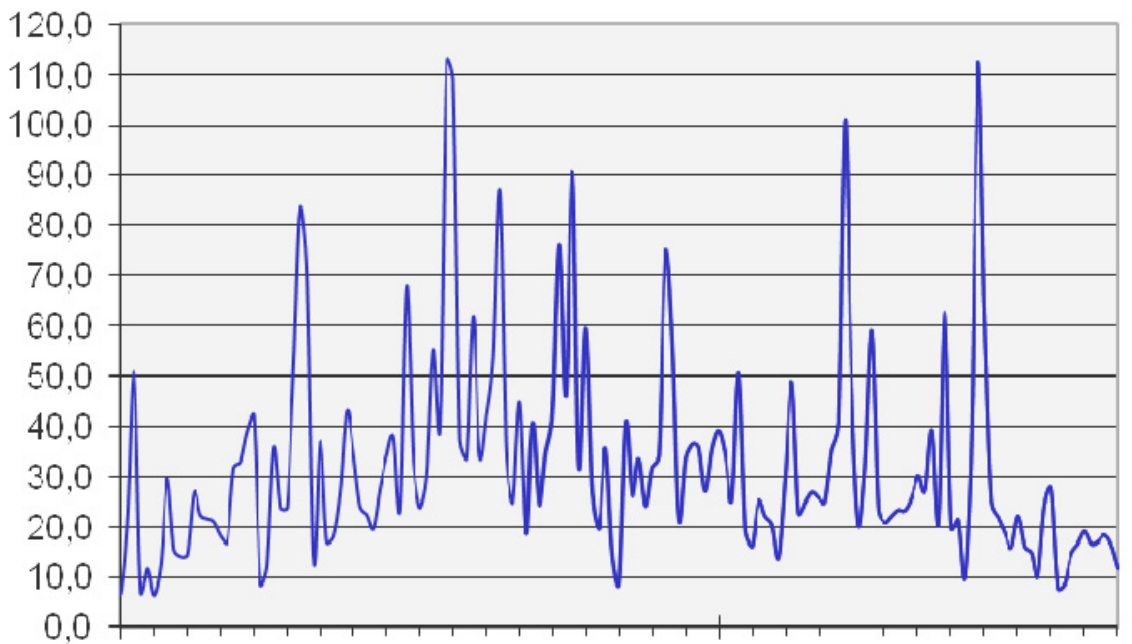

Figure 5: Daily mean air exchange rate with cross ventilation for room A.

Air exchange rate in $1 / \mathrm{h}$. May - September

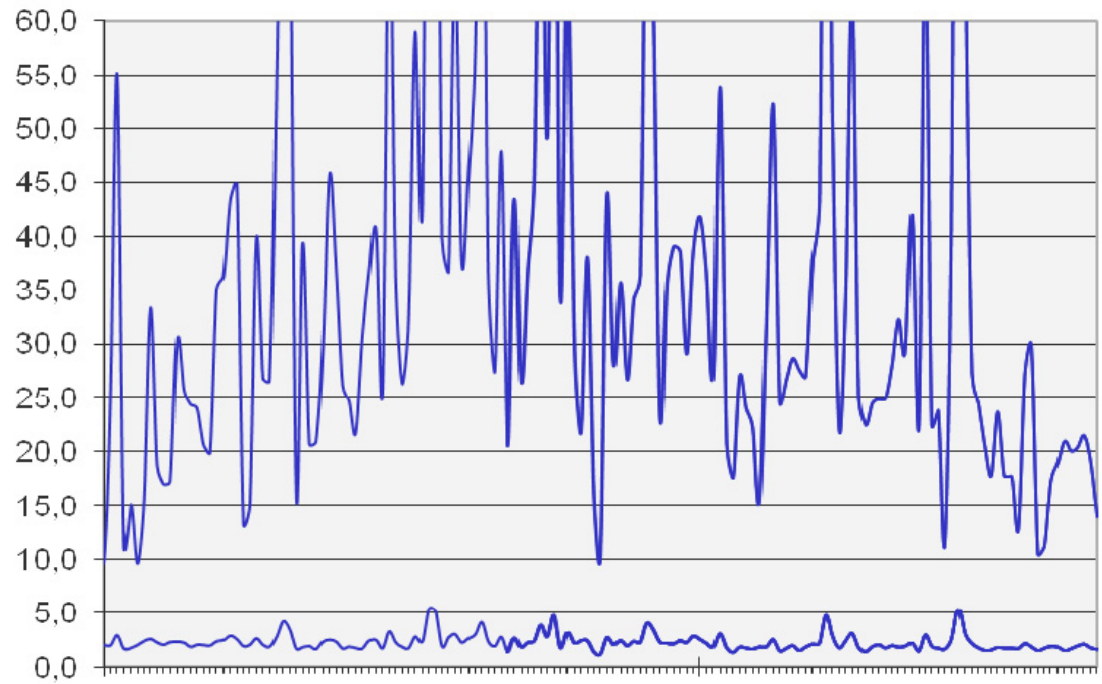

Figure 6: Daily mean air exchange rate with cross ventilation (top line) and without cross ventilation (bottom line) in room B. 


\subsubsection{Parameter}

At first it was looked at the impact of the solar heat gains. It showed that the shutters of the windows are a very important parameter. Closing them for shading when the sun is shining results in a lower temperature in the rooms in the summer.

A second parameter is the ventilation. At a higher rate than $4,5 / \mathrm{h}$ there is no more benefit for the cooling of the rooms and the user will close the windows for more comfort. It was estimated that the windows are always closed when the outside temperature is below $5^{\circ} \mathrm{C}$ and higher than $30^{\circ} \mathrm{C}$. Cross ventilation is possible in all rooms, even at night.

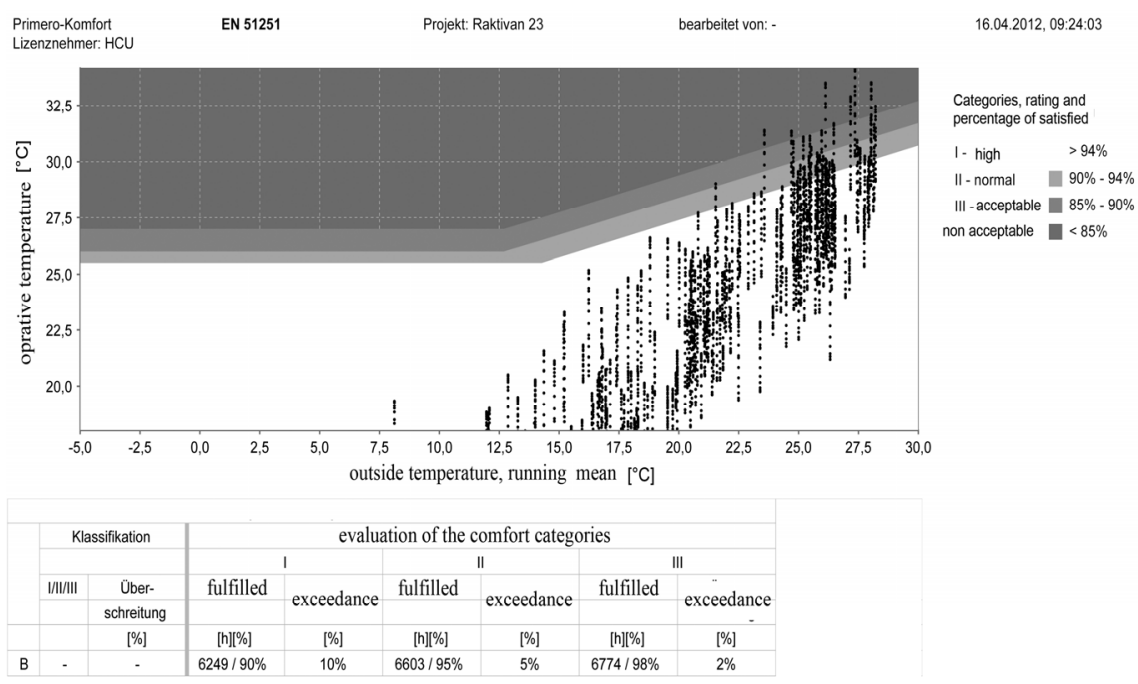

Figure 7: Comfort classification, EN 15251 [6].

A third factor is the building materials. As shown in Fig. 8 there is reasonable comfort reached with the building materials traditionally used.

\subsubsection{Comfort model}

The adaptive comfort model EN 15251 [6] differs between naturally ventilated and air conditioned buildings. In naturally ventilated building the people feel comfortable at noticeably higher temperatures. EN 15251defines three different comfort classes:

I. Highest standard, for special use

II. Good standard, for all new buildings

III. Low standard, acceptable for refurbished buildings

According to EN 15251 an exceedance of the comfort zones by 3-5\% is tolerated. Figure 8 shows a comfort diagram according to EN 15251. Assuming an optimal user behaviour for the passive measures the comfort zone III (non 
acceptable) will only be exceeded in $2 \%$ (equivalent to 7 days/year) of the time. An exceedance of 5\% (equivalent to 18 days per year) will occur for comfort zone II (normal comfort). For $90 \%$ of the time the comfort zone I (high comfort) is reached.

\subsubsection{Results of the simulation}

Without the shading of the windows with shutters the simulation calculates the days per year exceeding comfort zone II with 25 days and comfort zone III with 14 days (non acceptable temperature inside the building).

Combining the lack of shading with reducing the ventilation to only $2 / \mathrm{h}$, which simulates the situation without cross ventilation, it would lead to 25 days exceeding comfort zone III.

In a further step the simulation shows that an interior insulation can lead to comfort zone I throughout the summer whereas a light construction without brick masonry, no shading and no cross ventilation would highly decrease the comfort inside the rooms (comfort zone III will be exceeded in 45 days of the year and comfort zone II for 60 days).

\section{Conclusion}

The results of this research show the important effect of cross ventilation to avoid overheating in the summer with passive measures. Calculating the air exchange rate could prove that the ventilation of a room can be very high with wide openings on one side and only a small opening on the other. Closing this small opening reduces the ventilation of a room significantly and causes overheating in summer time.

Another important factor is the shutters on the windows. The solar heat gain in summer will lead to high temperatures inside the building without the shading on the windows. The shutters also have the function of protection against burglary to make night ventilation possible.

The third factor investigated has been the building materials. The construction of the upper floors, consisting of timber frames with brick masonry proved to have positive effects for the comfort inside the building.

To summarise the results it will be possible in further research to develop planning guidelines for the renovation of modern and not climate responsive houses in Greece on the basis of the strategies for passive cooling found by looking at the traditional architecture.

\section{References}

[1] Meteonorm, METEOTEST | Fabrikstrasse 14 | 3012 Bern | Switzerland

[2] Database taken from EnergyPlus, Energy Simulation Software, US Dept. of Energy, http://apps1.eere.energy.gov/buildings/energyplus/cfm/weather data. $\mathrm{cfm}$

[3] BS 5925-1991 Code of practice for ventilation principles and designing for natural ventilation, Publication from BSI. 
[4] Rijal, H. B.; Tuohy, P.; Nicol, F.; Humphreys, M. A.; Samuel, A.; Clarke, J. (2008): Development of an adaptive window-opening algorithm to predict the thermal comfort, energy use and overheating in buildings.

[5] PRIMERO 1.0, Primero Komfort, HCU Hamburg, www.primerosoftware.de

[6] EN 15251, Indoor environmental input parameters for design and assessment of energy performance of buildings addressing indoor air quality, thermal environment, lighting and acoustics, May 2007. 